\title{
Remediation of the high-level radwaste repositories at Russian Research Center "Kurchatov Institute"
}

\author{
A.V. Chesnokov, V.G. Volkov, Y.A. Zverkov, O.P. Ivanov, A.V. Lemus, \\ S.G. Semenov, V.E. Stepanov and A.D. Shisha \\ Russian Research Center "Kurchatov Institute", 123182 Moscow, Russia
}

\begin{abstract}
The paper presents peculiarities of organization and performance of activities on disposition of the high level activity radwaste repository located at the radwaste disposal site of the Russian Research Center "Kurchatov Institute" in Moscow. The process of the radwaste extraction from the repository is described in comparison with similar activities in other old repositories. Tools and equipment used for the radwaste extraction from the repository are listed. Conventional construction machines equipped with a hydraulic hammer or a clamshell were used for destruction of the concrete-encased radwaste mass and extraction of low-level radwaste. Intermediate- and high-level radwaste was extracted by remotely controlled robots operating inside the shielding structure. Gamma visor was used for detection of highlevel radwaste or fragments in the mass concrete being destroyed and for pointing remotely controlled robots accordingly. The paper describes peculiarities of radiation monitoring in the course of operations on disposition of the repository. For rapid detection of changes in radiation conditions in the working areas, there was used a gamma locator with on-line transmission of its data to a PC and their processing. The same measuring and extraction equipment were used for remediation of high-level radwaste repository at the Gas Plant complexes.
\end{abstract}

\section{INTRODUCTION}

In its radiation-hazardous objects' remediation activities, RRC "Kurchatov Institute" has to face the need to liquidate temporary repositories containing high-level radioactive waste. One of these facilities was situated at the temporary radwaste storage facility at the main RRC KI site and contained over 240 canisters with high-level waste. This repository (marked No 4) has been built in the end of 1950ies and contains high-level structural elements of RFT reactor, which has been decommissioned in the beginning of 1970ies. Repository No 4 is made of reinforced concrete and consists of three equal-size sections. Its external dimensions are: length $-20 \mathrm{~m}$, width $-7.2 \mathrm{~m}$, and height $-3.6 \mathrm{~m}$. When filled with waste, the repository was encased in high-strength concrete.

Another object was the repository of the Gas Plant situated at the separate RRC KI site at a 50-meters distance from the Moskva River bank. This repository was arranged in a separate building, has 3 equal-size sections and contained a bulk of high-level radiation protection elements and some structural elements of VVR-2 reactor, which has been shut down in the early 1980ies.

\section{LIQUIDATION OF THE ENCASED HIGH-LEVEL WASTE REPOSITORY}

The presence of high-level waste in the repository No 4 has required preliminary radiation monitoring of its contents, as well as computational assessments of possible changes of the radiation situation near the repository due to its opening and high-level waste extraction and removal operations. This was determined by the repository's location in the immediate vicinity of the Center's secured perimeter and high apartment houses. Computations have shown that the liquidation of this repository requires an external radiation shield. External support walls made of foundation blocks sized $600 \times 600 \times 2400 \mathrm{~mm}$ and reinforced with metallic trusses, which served as a basement for the external covering structure made 
of 6-m pavement slabs $(20 \mathrm{~cm}$ thick, Fig. 1). A labyrinth was constructed to allow robots' entering the operational area without any direct radiation releases from the radiation shield.

Color video cameras were installed for monitoring purposes inside the radiation shield. Signals from these cameras were displayed on the monitors of operators participating in the repository's liquidation. In order to notify the personnel of the radiation hazard, the working area was equipped by threshold collimation detectors, which generated audio and light alarm signals, if the established gamma dose rate was exceeded.

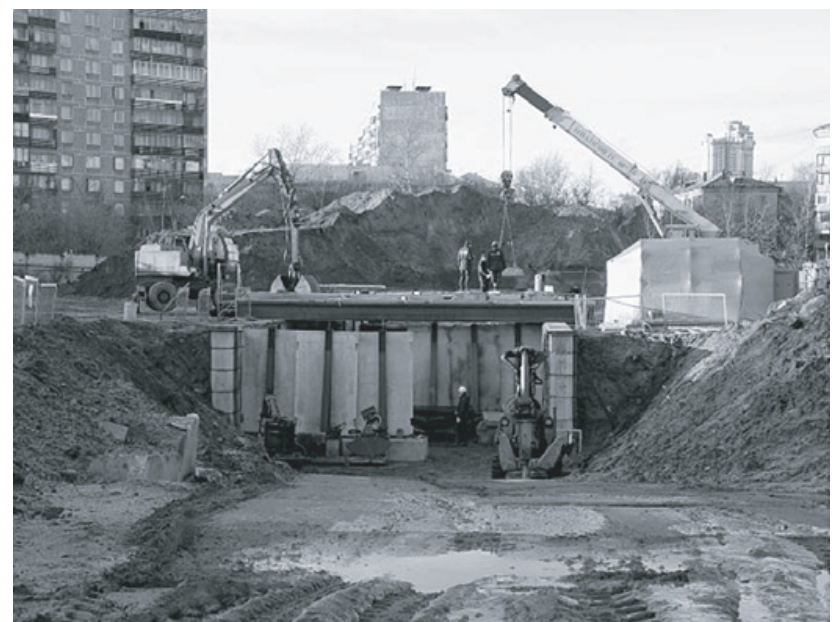

Figure 1. A view of the radiation shield of repository No 4.

The storage monolith was destroyed through upper apertures in the radiation shield using an excavator equipped with a hydraulic hammer. A gamma visor generating the signal displayed on the operator's monitor was used to detect canisters containing high-level waste in the destroyed monolith [1-3]. Removal of canisters containing high-level waste was a non-routine situation carried out by robots in conditions of high radiation fields (up to several dozens $\mathrm{mSv} / \mathrm{h}$ ). When canisters containing high-level waste were detected in the repository No 4, its upper radiation shield cover was restored completely, and high-level waste extraction, activity measurements and packaging was performed by robots inside the shield, with no personnel present in the high radiation area. Robots destroyed residues of the concrete waste matrix, gripped the detected high-level waste and removed them to the special grading area arranged inside the radiation shield. Within this area, robots performed all waste separation, cutting and packaging operations. Robots' steering to high-level sources, as well as these sources' extraction, fragmentation and packaging into containers were controlled on the gamma visor monitor (Fig. 2). Highlevel waste was placed into special KRAD-2,7 containers with 250-mm-thick concrete insert, and were removed from under the radiation shield in a packaged form ready for transportation to MosNPO Radon for ling-term disposal.

The radiation situation in the operational area and at the whole site during the works on the repository No 4 was controlled by two gamma locators, which measured the flux of ionizing radiation photons with account of its spectrographic parameters [4]. One gamma locator performed continuous monitoring of radiation situation in the operational areas of repository No 4, displaying the measured data on personal computer monitors via an Internet line. The second gamma locator scanned the whole site of old repositories and performed spot measurement of gamma spectra in its selected spots (Fig. 3). Based on the photon flux distribution data, gamma dose rates were calculated for all spots of the scanned area, which were represented in form of a color palette superposed on the calibrated image of the scanned object. 


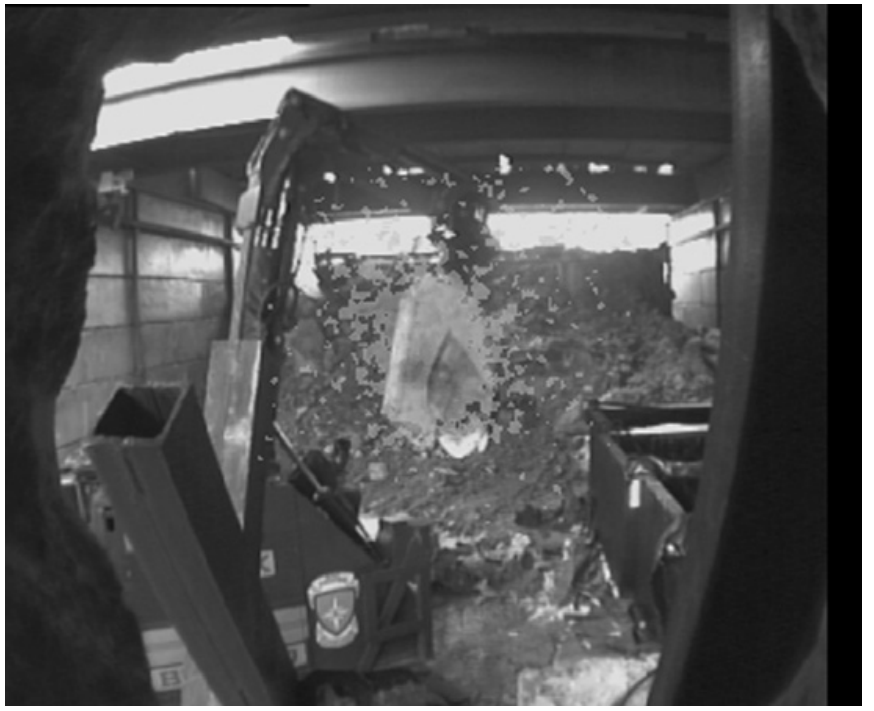

Figure 2. The moment of high-level radiation source's removal by the robot. This image was obtained using the gamma visor.

As a result, over $800 \mathrm{~m}^{3}$ of radwaste, including about $90 \mathrm{~m}^{3}$ of high-level waste was removed from the repository. The cumulative activity of this waste exceeded $7.5 \times 10^{12} \mathrm{~Bq}(\sim 200 \mathrm{Ci})$.
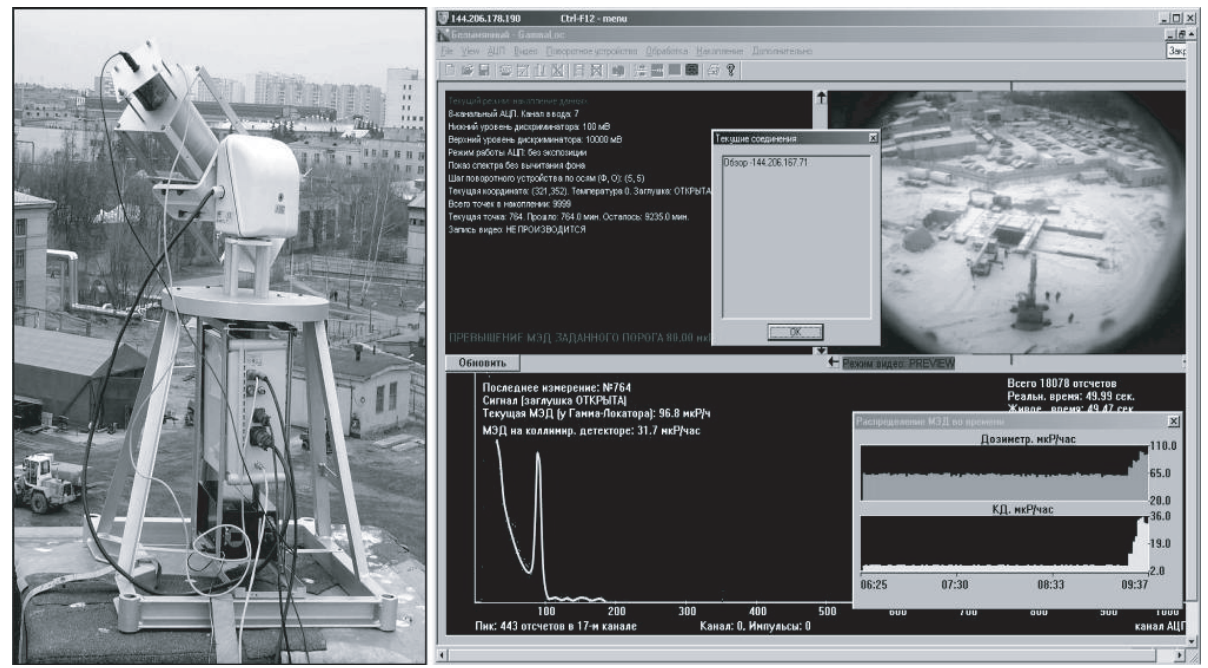

Figure 3. Image on the screen of the gamma locator during the works in repository No 4 (with shady shielding in place).

\section{REMOVAL OF HIGH-LEVEL WASTE FROM THE GAS PLANT REPOSITORY}

In 2006, RRC "Kurchatov Institute" also removed medium- and high-level radioactive waste from the repository in building 209 of the Gas Plant. This repository was filled in 1983, in the process 
of VVR-2 reactor decommissioning. This provisional repository is characterized by its location in the same building with a temporary spent nuclear fuel repository.

The above temporary repository of solid radwaste consists of 3 tanks faced with stainless steel. Each tank is sized $2900 \times 2000 \times 4935$ from the inside; the total repository volume makes about $60 \mathrm{~m}^{3}$. Storage tanks were covered from above with steel-faced concrete protective lids. The total weight of solid radwaste accumulated in the repository of building 209 made about 80 tons, and some dismantled structural and equipment elements reached up to 2 meters in size and up to 3.5 tons - in weight.

Canisters were removed from the repository by Brokk-330 robot; then they were sorted and packaged either in NZK-1,5, or in KRAD-2,7 containers having concrete inserts inside.

High-level protective semi-rings of the reactor were conditioned at a special site, where loaded and shipping-ready containers with radwaste have been previously stored. Brokk-33-robot placed semirings onto special slipways, and a drilling facility's rotary core bit bored holes in it along the semi-ring's symmetry axis. These works were performed using dust-suppression means in low-speed drilling mode. The personnel was used only in the process of steering the drilling facility to the boring spot.

Then Brokk-330, with its hydraulic hammer, broke semi-rings into two parts (Fig. 4) and packaged its halves into KRAD-2,7 container. Then contaminated waste and sand were added to fill the container.

After loading, all containers underwent control measurements of specific and total activity of radwaste contained into them.

These measurements were performed in accordance with the certified method of Cs-137 and Co-60 specific radioactivity measurement inside containers using a calibrated field spectrometric collimation detector [5].

Radiation spectra of radwaste placed inside the container have shown that its nuclide composition is largely heterogeneous: some casks contained mostly the waste with Co-60, and in other ones, along with it, Cs-137 also gave a significant contribution to the dose rate.

As a result, over $90 \mathrm{~m}^{3}$ of waste with total activity of about $1.7 \times 10^{11} \mathrm{~Bq}(\sim 5 \mathrm{Ci})$ was removed from the Gas Plant repository to the special site of MosNPO Radon.

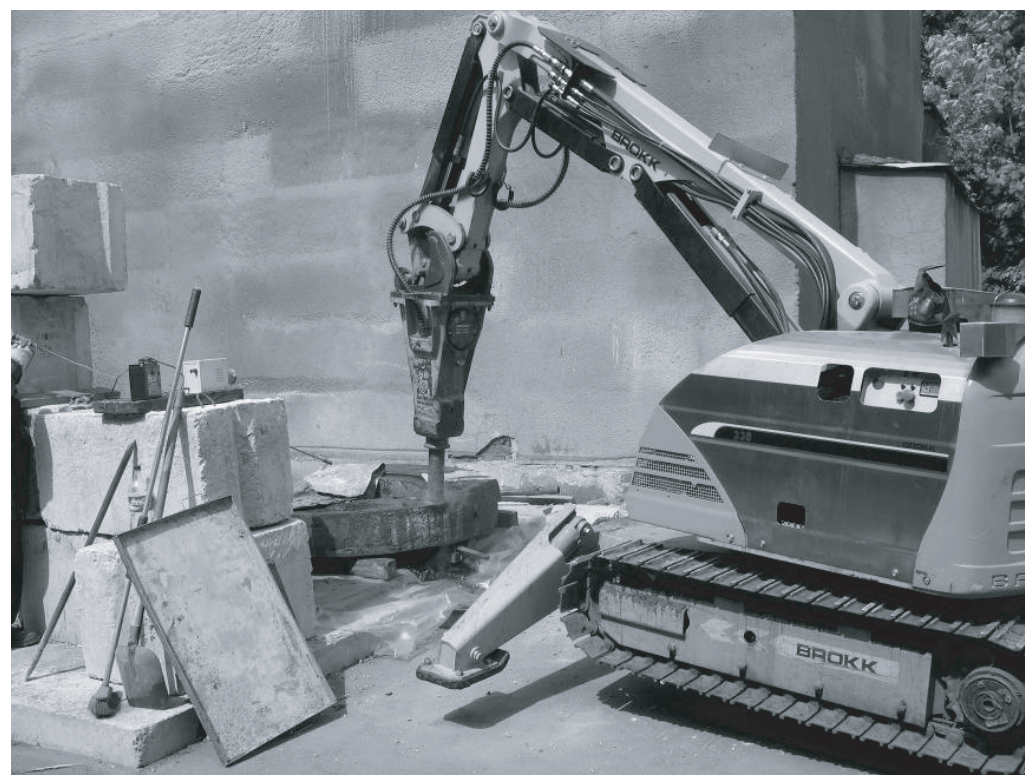

Figure 4. Destruction of a semi-ring by Brokk-330 hydraulic hammer. 


\section{RESULTS AND CONCLUSIONS}

The experience of high-level waste removal from temporary radwaste repositories allowed RRC KI to develop the technology of radwaste management without any direct contact of the personnel with intensive radiation sources. The works were performed by remote-control robots steered using a gamma visor, which had its monitor and control board installed in the radiation-safe area. The radiation situation was continuously monitored by gamma locators, which transmitted their measured data via Internet lines to monitors of all the responsible staff members participating in the works. This technology made it possible to remove high-level waste in a packaged form ready for shipping to long-term disposal sites, and to reduce dose burdens on the personnel involved in the related operations.

\section{Acknowledgments}

The authors thank N.N. Ponomarev-Stepnoy for his interest to their work and for his valuable comments.

\section{References}

[1] V.N. Potapov, S.M. Ignatov, O.P. Ivanov, et al. New Instruments and Radioactivity Measurement Methods Applied in Rehabilitation Activities at RWDS of RRC Kurchatov Institute. Proceedings of WM'05 Conference, Tucson, Arizona, February 27-March 3, 2005, CD-ROM.

[2] O.P. Ivanov, V.E. Stepanov, V.G. Volkov, et al. Application of Portable Gamma Camera During an Extraction of the Radioactive Wastes from Temporal Storage at Territory of RRC Kurchatov Institute, ICEM'05/DECM'05 Conference, Glasgow, Scotland, September 4-8, 2005, Session No: 11, ICEM05-ID: 1197, -p. 84.

[3] O.P. Ivanov, V.E. Stepanov, V.G. Volkov, A.G. et al. New Portable Gamma-Camera for Nuclear Environment and Its Application at Rehabilitation Works, Book of abstracts, Nuclear Science Symposium, Rome, 2004 IEEE Conference, p. 89.

[4] V.N. Potapov, N.K. Kononov, O.P. Ivanov. et al. A Gamma Locator for Remote Radioactivity Mapping and Dose Rate Control, Book of abstracts, Nuclear Science Symposium, Rome 2004 IEEE Conference, p. 88.

[5] V.G. Volkov, V.N. Potapov, O.P. Ivanov, et al. New Radiation Monitoring Devices and Systems and Their Use in Rehabilitation Operations at RRC KI Temporary Radwaste Storage Area. Proceedings of the $7^{\text {th }}$ International Conference "Safety of Nuclear Technologies. Radwaste Management", St. Petersburg, Russia, 27 September-1 October, 2004, ProAtom Publishers, 2004, p. 371-378. 
